\title{
st \\ Divulgação científica globalizada: potencialidades e riscos
}

Olival Freire Júnior

\section{Einstein, o olhar da relatividade}

Scientific American Brasil/Duetto Editorial, Série Gênios da Ciência, n. 6

São Paulo, 2005, 98 págs.

A edição especial da Scientific American Brasil dedicada a Albert Einstein exibe a qualidade e os limites do gênero divulgação científica, bem como os riscos relacionados à globalização da produção cultural. A escolha de Einstein para integrar a série Gênios da Ciência, a qual inclui edições dedicadas a Arquimedes, Descartes, Kepler, Newton e Feynman, dentre outros, foi mais que oportuna, tendo em vista o centenário de seus trabalhos seminais e as comemorações relativas ao Ano Internacional da Física. A edição brasileira é uma tradução da edição italiana, cujo texto foi coordenado por Silvio Bergia, que é professor de física e de filosofia da física na Universidade de Bolonha. A tradução brasileira teve a revisão técnica do físico e doutor em filosofia Adonai Sant'Anna.

A edição apresenta uma visão panorâmica quase exaustiva da multifacetada atividade científica de Albert Einstein, com várias matérias utilizando fortemente uma abordagem histórica, ou pelo menos cronológica, para apresentar as realizações científicas de Einstein. Algumas matérias são, também, de natureza biográfica e, como Einstein trabalhou em quase todas as áreas da física do século xx, a edição termina tendo o caráter de uma biografia do cientista germano-suíço-americano e de uma introdução à física do século xx. Desse modo, a revista apresenta as contribuições científicas de Einstein percorrendo um caminho que perpassa a relatividade restrita, a relatividade geral, a cosmologia, a grande unificação, a teoria quântica e a mecânica estatística. A juventude de Einstein, as vicissitudes ligadas à recepção da teoria da relatividade e da idéia do quantum de luz, os debates sobre a interpretação da teoria quântica, bem como a sua atividade política relacionada ao sionismo e ao pacifismo, merecem atenção nessa edição especial.

A revista Scientific American é, seguramente, o mais influente veículo de divulgação científica do mundo. Criada em 1845, a sesquicentenária revista norte-americana tem exibido uma notável capacidade de renovação. Se há uma crítica que não pode ser, em geral, a ela dirigida é a da falta de qualidade do conteúdo científico que veicula. 
Como gênero cultural, entretanto, a divulgação científica não se identifica com a exposição sistemática dos procedimentos científicos que conduzem aos resultados que são publicizados. Além de técnicas literárias específicas, centradas na tensão entre o rigor e a demanda de popularização, a divulgação científica, sendo um discurso sobre a ciência, também requer os recursos da filosofia, da história e da sociologia da ciência. Nesse sentido, esta edição permite uma exploração das potencialidades e dos limites do gênero e, sem a pretensão de uma análise exaustiva, eu tomo aqui para comentário dois aspectos positivos e duas deficiências da publicação.

A contribuição de Einstein para a análise crítica dos fundamentos da teoria quântica sofreu uma radical reapreciação entre os físicos no último quartel do século xx. $\mathrm{O}$ físico Sidnei Redner, analisando o padrão de citações de artigos publicados na revista norte-americana Physical Review, ${ }^{\mathbf{1}}$ enquadrou o artigo publicado por Einstein, Podolsky e Rosen, em 1935, como um trabalho clássico redivivo, ou uma "bela adormecida". Clássicos redivivos seriam "antigos artigos muito bem citados mas com o grosso dessas citações ocorrendo muito depois de sua publicação". De fato, aquele artigo havia recebido, em Physical Review, 36 citações antes de 1980 e 456 até junho de 2003. Contando as citações em outras revistas científicas, esse artigo já ultrapassou mais de 1000 citações. Nesse artigo, Einstein critica a suposta completude da teoria quântica, recorrendo a um experimento de pensamento representado por um sistema físico constituído por duas partículas que interagem e separam-se espacialmente, um experimento hoje conhecido pela sigla EPR. Para Einstein, tais sistemas exibiam mais propriedades físicas que aquelas descritas pela teoria quântica, daí a sua incompletude. Contudo, em meados da década de 1960, o físico irlandês John Bell mostrou que existia um conflito entre os sistemas imaginados por Einstein e as predições da teoria quântica e, em 1969, os físicos norte-americanos John Clauser e Abner Shimony mostraram que os resultados experimentais disponíveis não eram suficientes para decidir o conflito e propuseram um experimento viável, com fótons óticos, para resolver a questão. Desde então, e até os dias atuais, tais experimentos têm se multiplicado, levando à confirmação das predições da teoria quântica e à não confirmação das propriedades físicas, hoje denominadas de localidade, que Einstein supunha que tais sistemas deveriam exibir. O efeito físico previsto pela teoria quântica, denominado de emaranhamento, está hoje na base de um campo de investigação em pleno florescimento, o da informação quântica. Estamos, então, diante de uma curiosa situação na história da ciência. Os desenvolvimentos do final do século xx não confirmaram as expectativas de Einstein, mas ele tem o mérito de ter insistido em um tipo de problema que seus contemporâneos consideravam totalmente resolvido e, portanto, desprovido de interesse científico. 
Toda essa história está bem retratada na edição especial da Scientific American. Adicionalmente, ela evidencia bem a possibilidade de julgamentos científicos equivocados, mesmo quando emitidos pelos melhores cientistas, ao comentar o julgamento que Abraham Pais faz da crítica einsteiniana à teoria quântica. ${ }^{2}$ Pais, um dos grandes físicos do século xx e historiador da física no final da carreira, afirmou que "essa conclusão [argumento EPR] não afetou o desenvolvimento posterior da física e, provavelmente, jamais afetará." Ironicamente, esta afirmativa de Pais foi publicada em 1982, ano em que foram publicados também os resultados dos experimentos conduzidos pelo físico francês Alain Aspect, os quais foram decisivos para chamar a atenção da comunidade científica para o tema.

A edição se destaca, também, pela análise ponderada das respectivas contribuições de Einstein, do físico francês Henri Poincaré e do físico holandês Hendrik Lorentz para o desenvolvimento da teoria da relatividade, bem como das relações entre os três cientistas. Vários foram os físicos que trabalharam ativamente, na virada do século xix, sobre os problemas associados à eletrodinâmica dos corpos em movimento. Discernir as influências mútuas e os créditos de cada um desses protagonistas tem sido um desafio permanente para os historiadores da ciência, e a edição passou bem pelo teste.

Apesar do anúncio de Silvio Bergia de que a edição apresenta Einstein "como cientista de seu tempo e não como mito", em um aspecto crucial, a edição rende-se ao mito. Da multilateral atividade política de Einstein, retratou-se apenas aquelas posições menos incômodas ao estado norte-americano: o sionismo e a posição pacifista, mesmo assim apresentando-as de modo excessivamente aligeirado. Ora, a principal novidade nesse terreno começa a aparecer em 2002, quando o jornalista norte-americano Fred Jerome publica o livro The Einstein file, baseado no dossiê que o FBI organizou sobre o cientista, e que o jornalista conseguiu recuperar. ${ }^{3}$ A própria existência desse enorme dossiê altera a história do século xx, porque ele foi coletado em função do plano do todo-poderoso chefe do FBI, J. Edgar Hoover, visando à expulsão dos Estados Unidos, sob a acusação de militância comunista, daquele que foi o mais ilustre refugiado judeu a adquirir a cidadania americana no século. $\mathrm{O}$ dossiê não levou a nada devido à insuficiência de evidências e à morte de Einstein em 1955. Recuperado dos arquivos por Fred Jerome, o dossiê revela uma faceta da atividade política de Einstein pouco popularizada até hoje. Ele foi um ativo defensor das liberdades civis, defendendo a desobediência civil como recurso contra a histeria anticomunista que tomou conta dos Estados Unidos no período conhecido como macartismo. Ele foi também um ostensivo 
crítico da discriminação racial então dominante, ligando-se estreitamente a líderes negros norte-americanos como o atleta e artista Paul Robeson e o historiador W. E. B. du Bois. O livro de Jerome não passou desapercebido. Ele foi um dos três autores convidados por Peter Galison para escrever a seção "Focus" da tradicional revista Isis (v. 95, n. 4, 2004), a qual foi dedicada às contribuições das novas investigações históricas para a modificação da imagem que temos construído de Albert Einstein. Infelizmente, nada desse novo conhecimento histórico encontrou abrigo nesta edição especial.

Scientific American se orgulha de ser hoje um produto da economia globalizada. Ela foi adquirida em 1986 pelo grupo editorial alemão Verlagsgruppe Georg von Holtzbrinck, é editada em quinze línguas além do inglês e tem mais de um milhão de exemplares em circulação no mundo. O mercado globalizado tende a padronizar os produtos culturais e a dissolver as culturas locais e nacionais. Esta assertiva, que poderia parecer excessivamente ideológica, é bem ilustrada por essa edição especial. Como a edição brasileira é a mera tradução da edição italiana de Scientific American, aspectos essenciais da atividade de Einstein relacionados ao Brasil foram omitidos. Observo, incidentalmente, que quase todas as comemorações do Ano Internacional da Física no Brasil realçaram tal atividade. Caso os sócios brasileiros desse empreendimento estivessem atentos para a dimensão local dos produtos culturais, eles poderiam ter procurado os pesquisadores brasileiros e estrangeiros que têm investigado exaustivamente, por exemplo, a expedição astronômica a Sobral, no Ceará, para verificar a deflexão de raios luminosos por ocasião do eclipse de 1919, o que foi um teste da relatividade geral, transformando subitamente Einstein em uma figura conhecida além dos círculos científicos; ou, ainda, ter explorado a visita de Einstein ao Brasil e à Argentina em 1925. Correndo o risco de omissões, cito uma lista de pesquisadores que dedicam atenção ao tema: Alfredo Tolmasquim, Michel Paty, Ildeu Moreira, Augusto Videira e Jerônimo Alves. ${ }^{4}$ A presença de uma foto do Museu do Eclipse, em Sobral, na ilustração da edição (p. 52), sem que o texto justifique tal inclusão, evidencia o sentimento de culpa dos editores brasileiros por esse esquecimento.

\author{
Olival Freire Júnior \\ Professor Titular do Instituto de Física, \\ Universidade Federal da Bahia. \\ freirejr@yahoo.com.br
}

\footnotetext{
${ }_{4}$ Dentre as diversas publicações desses autores sobre o assunto, destaco Alfredo Tolmasquim, Einstein: o viajante da relatividade na América do Sul, Rio de Janeiro: Vieira \& Lent, 2003; e Ildeu Moreira e Antonio Videira (Org.), Einstein e o Brasil, Rio de Janeiro: Editora UFRJ, 1995.
} 